\title{
Determinantes das atitudes do eleitorado brasileiro com relação à privatização e aos serviços públicos
}

\author{
Elizabeth Balbachevsky \\ Denilde Oliveira Holzhacker
}

Universidade de São Paulo

\begin{abstract}
Resumo
Este trabalho investiga possíveis efeitos do processo de privatização de empresas estatais, levado à cabo pelo governo FHC, sobre as atitudes e opiniões do eleitorado brasileiro acerca da presença do Estado na economia. O estudo utiliza um survey pós-eleitoral realizado no final do ano de 2002, que constitui a base de dados ESEB (Estudo Eleitoral Brasileiro), patrocinada pela CAPES. A investigação está centrada na análise dos padrões de respostas dados pelos entrevistados, quando solicitados a opinar sobre qual setor -iniciativa privada ou governo - deveria ser responsável pelo provimento de diferentes serviços e produtos à população. A análise encontrou uma forte coerência nessas respostas, o que permitiu produzir uma escala de atitudes relativa à privatização. Ademais, foi possível estabelecer correlações significativas entre essas atitudes e a campanha eleitoral de 2002, particularmente o voto declarado pelo eleitor.
\end{abstract}

Palavras-chave: Brasil, privatização, opinião pública, estatismo, decisão eleitoral.

\begin{abstract}
This paper analyzes the possible impacts of the privatization process implemented by the Brazilian former President, Fernando Henrique, over the attitudes and opinions held by Brazilian electorate regarding the presence of the state in the economy. Te paper uses a post-electoral survey from 2002 The ESEB (Brazilian Electoral Study) data-base - supported by CAPES Foundation. The inquiry carried out in the paper centers on different patterns found in the answers given by the respondents when asked which sector - either government or private one - should be in charge of providing different products and services. The study found out an impressive degree of coherence in the answers given by the respondents, which were used to propose a scale for different attitudes regarding the privatization process. Furthermore, it was possible to establish significant correlation between this attitude and the electoral campaign and the declared vote of the respondent.
\end{abstract}

Key words: Brazil, privatization, public opinion, statism, electoral decision 


\section{Introdução}

Não surpreende o interesse crescente da literatura internacional acerca do impacto das privatizações e das reformas econômicas nas visões e percepções dos latino-americanos. Este tema tem sido abordado principalmente na sua relação com o apoio à democracia e às instituições políticas ${ }^{1}$. 0 processo de privatização foi alvo de debates e redundou em clivagens relevantes no interior das elites econômicas e políticas, e também em alguns segmentos da sociedade brasileira. O contexto conturbado que cercou a privatização das empresas estatais no Brasil gerou um grande interesse na literatura acerca da compreensão dos seus efeitos (ARRETCHE, 2002).

No final da década de 1950, Juscelino Kubistchek inaugurou um modelo de desenvolvimento sustentado por uma política industrial agressiva, que reservava um grande espaço para a presença do Estado na economia, especialmente em setores considerados estratégicos. Este modelo estatizante foi aprofundado nos anos 1970, com a expansão do espaço de atuação das empresas estatais. Entre 1966-77 foram criadas 219 empresas estatais, nos mais diversos setores econômicos. Este período foi marcado por fortes investimentos internos e externos em grandes projetos voltados para alavancar o crescimento econômico, que contavam com forte presença de recursos públicos (NASCIMENTO, 2003).

Afetado pelas crises internacionais durante os anos 1970 e 1980, o período posterior é marcado pelo alto endividamento externo, por uma forte inflação e pelo esgotamento da capacidade de investimento do Estado. Esse cenário levou os governos a aplicarem diferentes planos econômicos - todos mal-sucedidos buscando reverter a situação de estagnação econômica do país ${ }^{2}$. Nos anos 1990, o país passou por uma profunda reformulação da estrutura do Estado e de suas relações com o mercado e a sociedade. As idéias e políticas propostas pelo Consenso de Washington ${ }^{3}$ ocupam grande parte do debate interno e externo. A

\footnotetext{
${ }^{1}$ Graham e Sukhtankar (2004) apresentam uma revisão da literatura que analisa os efeitos das reformas econômicas entre os cidadãos dos países latino-americanos. Esses autores argumentam que há uma grande variedade de trabalhos que buscam relacionar as reformas econômicas e os processos democráticos da América Latina. Os dois autores analisam as informações do survey Latinobarômetro, entre 2000-2001, associando as recentes crises econômicas na região à redução do apoio à democracia.

2 Durante os anos 80 foram aplicados diferentes programas que se baseavam na hiperdesvalorização, como forma de aumentar as exportações e o crescimento econômico. Foi um período marcado pela estagnação econômica e desconfiança política. Entre 1986.87, durante o primeiro governo democrático após o período autoritário, foi implementado o Plano Cruzado, entre outros. Durante o governo Collor (1990) foi estabelecido o confisco que extinguiu qualquer possibilidade de volta da credibilidade dos agentes econômicos na retomada do crescimento econômico.

${ }^{3}$ O Consenso de Washington consiste numa série de princípios sugeridos pelo economista John Williamson, em 1989, que deveriam guiar os países em desenvolvimento para a retomada do crescimento. As políticas propostas consistiam em: disciplina fiscal; prioridade para gasto público em educação e saúde; reforma
} 
privatização das empresas estatais foi então proposta como uma peça fundamental no processo de reestruturação da economia. Outro aspecto importante dessas mudanças era a abertura econômica, considerada essencial para o controle da inflação, a modernização da indústria nacional e sua inserção no mercado globalizado 4 .

Como em outros países da América Latina, a privatização brasileira foi motivada pela crise financeira no setor público. Os subsídios das empresas estatais tinham forte impacto no déficit do setor público e deterioravam as finanças públicas. Outro fator que favorecia a implementação dessa política diz respeito ao esgotamento e deficiência de alguns serviços públicos, principalmente nos setores de energia e telefonia. As empresas estatais desses setores não tinham capacidade de investimento suficiente para suprir a demanda em expansão e acompanhar as mudanças tecnológicas mantendo a qualidade dos serviços ofertados (KUCZYNSKY, 2004).

No governo Fernando Henrique (1994-1998) o processo de reestruturação estatal foi aprofundado. A privatização foi retomada se convertendo em um dos pilares do plano de estabilização econômica, o Plano Real. Esse plano constitui-se em três fases, com objetivos e medidas específicas, como se vê no Quadro 1 abaixo.

\section{Quadro 1}

Governo FHC: Plano Real e suas fases

\begin{tabular}{|c|c|c|}
\hline Fases & Objetivos & Medidas \\
\hline 1 & $\begin{array}{c}\text { Garantir o equilíbrio das contas públicas } \\
\text { no curto prazo }\end{array}$ & $\begin{array}{c}\text { Elaboração do orçamento de 1994 e criação } \\
\text { do Fundo Social de Emergência 94/95 }\end{array}$ \\
\hline $2 / 3$ & Reforma monetária & $\begin{array}{c}\text { Criação da URV (Unidade Real de Valor) e do } \\
\text { Real (conclusão da reforma monetária) }\end{array}$ \\
\hline 4 & $\begin{array}{c}\text { Consolidação da reestruturação do brasileiro e equilíbrio das contas } \\
\text { públicas no longo prazo }\end{array}$ & $\begin{array}{c}\text { Reformas: patrimonial (privatizações); } \\
\text { administrativa; previdência; tributária }\end{array}$ \\
\hline
\end{tabular}

Fonte: NASCIMENTO (2003, p. 197).

\footnotetext{
fiscal; taxas de juros positivas geradas no mercado; câmbio competitivo; política comercial liberal; abertura dos investimentos diretos estrangeiros; privatização; desregulamentação; defesa da propriedade privada redução do Estado na economia (WILLIAMSON, 2004).

4 O Programa Nacional de Desestatização (PND) tinha como objetivo: (1) a reordenação da posição estratégica do estado na economia; (2) saneamento do setor público; (3) fortalecimento do mercado de capitais (através da oferta de valores imobiliários); (4) modernização do parque industrial brasileiro.
} 
De acordo com Almeida (1999), entre 1991 e 1998, 63 empresas controladas pelo governo federal foram privatizadas ${ }^{5}$ e o Plano Diretor da Reforma do Aparelho do Estado (1995), implementado durante o governo FHC, implicou na privatização de várias empresas estatais. Esse plano também previa a concessão, para a exploração da iniciativa privada, de bens e serviços considerados de utilidade pública ${ }^{6}$. De acordo com essa opção estratégica, o Estado deveria concentrar sua atuação no papel regulador e não mais como provedor econômico.

Almeida (1999) argumenta que o processo de reforma econômica deve ser analisado a partir da perspectiva dos dilemas da ação coletiva, conflitos distributivos e também considerando como os políticos avaliam os impactos da reforma nas suas opções e chances eleitorais ${ }^{7}$. A partir dessa última perspectiva é relevante analisar como essa política mobilizou as visões e percepções dos atores envolvidos.

Até o final dos anos setenta, as empresas públicas eram, na visão da população e da elite, símbolos do processo de industrialização do país (ALMEIDA, 1999). Essa percepção benigna e até positiva das empresas estatais permaneceu ao longo da década de oitenta. Ainda de acordo com Almeida (1999), esse consenso só alterou-se lenta e gradualmente, com a instauração do processo democrático, no final dos anos oitenta e início da década de noventa.

Nesse quadro, o diagnóstico neoliberal sobre a falência do Estado e a necessidade de implementação de políticas de privatização chocava-se com as posições desenvolvimentistas que prevaleceram nos países da América Latina até então. No início dos anos 1990, muitos setores ainda defendiam um projeto de econômico bastante intervencionista, baseado na ação do Estado, dirigindo, apoiando e supervisionando a industrialização de setores considerados estratégicos. O grau de dissenso entre a elites acentuava os conflitos em torno das prioridades econômicas e sociais. Diniz (2002) argumenta que prevalecia um grande desacordo quanto ao esgotamento do modelo desenvolvimentista e o debate político ainda era permeado pela questão da soberania e do projeto nacional. Nesse enquadramento, as empresas estatais eram vistas como instrumentos necessários para a política econômica e industrial.

\footnotetext{
${ }^{5}$ Entre 1990 e 1992 (governo Collor) foram vendidas 18 empresas; entre 1993 e 1994 (governo Itamar) foram vendidas 15 empresas; entre 1995 e 1998 (governo Fernando Henrique) foram vendidas 30 empresas controladas pelo governo federal, dentro do Plano Nacional de Desestatização. Em 1998, foram vendidas as empresas do setor de telecomunicações. Entre 1990 e 1998 o ingresso total foi de US\$ 62.087 milhões (ALMEIDA, 1999, p. 432).

${ }^{6}$ Foram introduzidas mudanças institucionais importantes que permitiram a inclusão de empresas de telecomunicações, eletricidade, navegação de cabotagem, gás e petróleo, que eram monopólios estatais.

${ }^{7} \mathrm{~A}$ autora considera as reformas econômicas como bens públicos que sofrem os efeitos da ação coletiva, ou seja, de um lado, envolve a avaliação dos resultados em que os custos são imediatos e os benefícios tendem a ser difusos, dessa forma, aqueles que se opõem a mudança tendem a se organizar para bloqueá-las; por outro lado, a ação coletiva também envolve a posição dos políticos, que buscam maximizar seus ganhos eleitorais.
} 
Na posição oposta, a proposta da privatização das empresas públicas passa por dois argumentos. O primeiro refere-se à diferença de eficiência e produtividade entre empresas públicas e privadas. As empresas públicas não teriam incentivos para se adequarem às necessidades de mercado, pois falta a pressão para a geração de lucro e para a busca de maior produtividade. A lógica privada baseada na busca pela eficiência e lucratividade produziria empresas mais eficientes e atentas às necessidades do mercado consumidor (LOURENÇO NETO, 2002).

O contra-argumento aponta o papel estratégico das empresas estatais na consolidação do desenvolvimento econômico. Desobrigadas de buscar o lucro, elas estariam melhor posicionadas para atender a sociedade como um todo (e não apenas o mercado). Portanto, elas atenderiam melhor as necessidades da massa carente que compõe a maior parte da sociedade brasileira. Além disso, a empresa estatal, por não sofrer a lógica da competição econômica, estaria em condições para planejar sua atuação por largos períodos de tempo, contribuindo para o desenvolvimento econômico de longo prazo do setor onde ela opera.

As repercussões desse debate nas elites brasileiras são bem analisadas por Lima e Boschi (1995), quando descrevem as diferentes visões da reforma econômica realizada no Brasil. O estudo propõe dois índices: o primeiro, denominado de orientação em face do ajuste, inclui as avaliações das elites no que diz respeito ao processo de reestruturação econômica, ou seja, sobre desregulamentação da economia, privatização das empresas estatais, abertura comercial e eliminação das restrições ao capital estrangeiro; e o segundo, chamado de orientação em face da modernização do Estado, compõe-se das avaliações sobre as privatizações dos serviços públicos, das estatais, redução do número de funcionários públicos e supressão da estabilidade do funcionalismo (LIMA e BOSCHI, 1995, p. 14). A análise dos autores mostra diferenças entre grupos empresariais e sindicais quanto à visão mais ou menos favorável do processo de modernização do Estado. Entre as reformas, a que obteve menor apoio entre as elites foi a privatização, exceção feita aos grupos empresariais, francamente favoráveis ao processo. Os autores também sugerem uma "anti-cultura de mercado" presente nas elites brasileiras. Com isso se referem ao forte apoio à intervenção do Estado na economia e preferência por critérios de igualitarismo em detrimento da eficiência. Os empresários mais uma vez, foram o ponto de maior discordância com relação essas questões, enquanto os demais setores (congressistas, administra-dores públicos e sindicalistas) posicionaram-se entre medianamente favorável à totalmente favorável (LIMA e BOSCHI, 1995, p. 19).

Entretanto, não há na literatura brasileira análises que busquem entender como o processo de privatização é percebido pela sociedade em geral. Baker (2002) argumenta que as análises sobre o eleitorado brasileiro pautam-se pela percepção clássica dos estudos norte-americanos, que consideravam os eleitores 
"irracionais". Para a literatura brasileira, temas que envolvem maior densidade política tem baixo impacto nas decisões dos eleitores. A explicação usual se apóia em referências à baixa escolaridade dos eleitores. Esse quadro se compõe com a força das relações clientelistas, que não dariam espaço para o debate sobre temas políticos (BAKER, 2002) ${ }^{8}$.

Todavia, é possível contra-argumentar que o processo de reforma econômica teve impactos diretos na qualidade, eficiência e custos de serviços e produtos antes sob a responsabilidade de empresas estatais. Esses efeitos afetaram o dia-a-dia da população e podem ter conseqüências para as atitudes da população com relação ao processo de privatização dos serviços públicos.

A literatura internacional sobre eleições indica que as decisões governamentais sobre taxas e serviços públicos tendem a mobilizar as preferências eleitorais (HARROP e MILLER, 1987; GLYNN et al., 1999). O desempenho do governo nessa área é reconheci-damente importante para a definição do voto. Se os resultados forem favoráveis, o governo tenderá a ganhar a eleição; ao contrário, se forem negativos, tenderá a perder (SINGER, 2000, p. 101). Fiorina (1981) sugere que os eleitores escolhem seu candidato de acordo com a avaliação que fazem do seu desempenho quando no governo. A qualidade dos serviços públicos é uma importante referência nessa avaliação. Fiorina considera que esses serviços são relevantes por estarem próximos dos indivíduos e terem forte impacto no bem-estar pessoal. Assim, a maneira como eles são avaliados tem relevante impacto na decisão eleitoral. As privatizações e a avaliação da qualidade dos serviços prestados seriam fatores importantes para a compreensão das atitudes dos eleitores.

De acordo com Rattsø e Sørensen (2002), as reformas econômicas tendem a indicar conflitos de interesses entre os grupos. Esses conflitos podem ser percebidos entre os eleitores mais ou menos sensíveis ao processo. Dessa forma, a avaliação da eficiência da reforma será uma questão importante para os eleitores no processo eleitoral. Além disso, como assinalam esses autores, o processo de desregulamentação e privatização, em geral tende a ser acompanhado por um forte componente ideológico.

Este artigo pretende contribuir para esse debate, analisando como o processo de privatização teve impacto sobre a percepção dos eleitores brasileiros a cerca dos benefícios e da própria legitimidade da ação estatal em diferentes áreas e serviços de interesse público. Para alcançar esse resultado ele busca analisar as atitudes dos eleitores com relação à "desiderabilidade" ou não da presença do Estado na economia, a partir dos dados de pesquisas de opinião pública.

\footnotetext{
8 Baker (2002) análise o impacto das privatizações na decisão do eleitor brasileiro em 1998 . O autor análise os dados do survey "Mirror on the Americas", conduzido pelo The Wall Street Journal Americas, em 1998.
} 


\section{0 que dizem os dados}

Os dados que analisamos neste trabalho foram colhidos num survey póseleitoral realizado em 2002, com uma amostra nacional de 2514 entrevistados. 0 questionário aplicado incluía uma questão que listava um conjunto de serviços essenciais e de infra-estrutura, indagando se a responsabilidade pelo fornecimento de cada um desses serviços deveria ser do Estado ou das empresas privadas. A lista apresentada é extensa. A matriz das correlações (Tabela 1) mostra que as respostas dadas pelos entrevistados para cada um desses itens estão significativamente correlacionadas.

Esses resultados não são totalmente inesperados, considerando-se o fato de que os itens foram apresentados em uma lista que, até certo ponto, induz a repetição da resposta anterior. Entretanto, uma análise mais atenta dos padrões de correlação observados indica que há uma variação importante na magnitude do valor da correlação entre diferentes itens. Essa variação permite identificar alguns conjuntos de itens em que as respostas dos entrevistados estão significativamente mais fortemente associadas do que em outros.

Assim, por exemplo, a correlação entre serviços de saúde e educação alcança o alto valor de 0,668. Da mesma forma, as correlações que se verificam entre fornecimento de água e serviço de esgoto é de 0,767, indicando que, aos olhos da população, esses serviços são "o mesmo" serviço, do ponto de vista da "desiderabilidade" ou não da presença do Estado. O fornecimento de água está também fortemente correlacionado com os serviços de recolhimento de lixo $(0,557)$, o fornecimento de energia elétrica (0,575), o mesmo acontecendo com serviço de esgoto, onde as correlações são, respectivamente, 0,640 e 0,529.

Também as respostas dadas pelos entrevistados quando consideravam o fornecimento de telefonia fixa e celular estão fortemente correlacionadas, alcançando o valor de 0,614. Finalmente, no outro extremo, pode-se verificar uma forte correlação entre os serviços bancários e a fabricação de carros, onde a correlação também alcança o valor de 0,521. O padrão de respostas para telefonia celular está fortemente correlacionado com as respostas observadas entre telefonia fixa e a fabricação de carros: em cada um dos casos, a correlação observada foi de, respectivamente, 0,435 e 0,497. O leitor poderá observar que em todas as outras células, as correlações observadas são mais baixas. Esses resultados indicam que as respostas de cada eleitor para os diferentes itens da lista variaram bastante, porém seguindo padrões previsíveis. Assim, para o eleitorado brasileiro, alguns desses serviços são, claramente, de responsabilidade do Estado. Outros são vistos como atributos quase que exclusivos da iniciativa privada e outros ainda provocam uma polarização, com parte do eleitorado tendendo a associá-los à esfera do Estado e outra parte atribuindo-os à iniciativa privada. 
BALBACHEVSKY, E.; HOLZHACKER D. O. Determinantes das atitudes do eleitorado brasileiro...

Tabela 1

Matriz de correlação dos itens de avaliação da responsabilidade dos serviços públicos e infra-estrutura

\begin{tabular}{|c|c|c|c|c|c|c|c|c|c|c|c|c|c|}
\hline & 吾 & 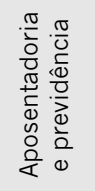 & 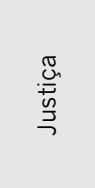 & 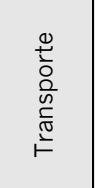 & 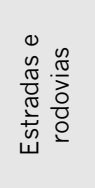 & 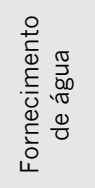 & 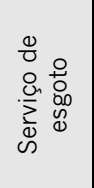 & 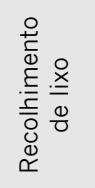 & 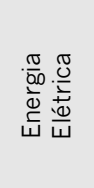 & $\begin{array}{l}\frac{0}{x} \\
\frac{x}{4} \\
\frac{0}{0} \\
\frac{0}{0} \\
\frac{0}{0} \\
\vdash\end{array}$ & 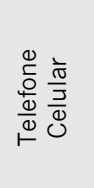 & $\begin{array}{l}n \\
0 \\
0 \\
\frac{0}{\pi} \\
\infty\end{array}$ & 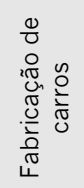 \\
\hline Educação & $\begin{array}{c}0,668 \\
(* *)\end{array}$ & $\begin{array}{c}0,398 \\
(* *)\end{array}$ & $\begin{array}{c}0,303 \\
(* *)\end{array}$ & $\begin{array}{c}0,306 \\
(* *)\end{array}$ & $\begin{array}{c}0,307 \\
(* *)\end{array}$ & $\begin{array}{c}0,252 \\
(* *)\end{array}$ & $\begin{array}{c}0,261 \\
(* *)\end{array}$ & $\begin{array}{c}0,247 \\
(* *)\end{array}$ & $\begin{array}{c}0,242 \\
(* *)\end{array}$ & $\begin{array}{c}0,189 \\
(* *)\end{array}$ & $\begin{array}{c}0,186 \\
(* *)\end{array}$ & $\begin{array}{c}0,243 \\
(* *)\end{array}$ & $\begin{array}{c}0,175 \\
(* *)\end{array}$ \\
\hline Saúde & & $\begin{array}{c}0,460 \\
(* *)\end{array}$ & $\begin{array}{c}0,364 \\
(* *)\end{array}$ & $\begin{array}{c}0,303 \\
(* *)\end{array}$ & $\begin{array}{c}0,331 \\
(* *)\end{array}$ & $\begin{array}{c}0,286 \\
(* *)\end{array}$ & $\begin{array}{c}0,284 \\
(* *)\end{array}$ & $\begin{array}{c}0,248 \\
(* *)\end{array}$ & $\begin{array}{c}0,279 \\
(* *)\end{array}$ & $\begin{array}{c}0,220 \\
(* *)\end{array}$ & $\begin{array}{c}0,194 \\
(* *)\end{array}$ & $\begin{array}{c}0,275 \\
(* *)\end{array}$ & $\begin{array}{c}0,175 \\
(* *)\end{array}$ \\
\hline $\begin{array}{c}\text { Aposentadoria } \\
\text { e previdência }\end{array}$ & & & $\begin{array}{c}0,352 \\
(* *)\end{array}$ & $\begin{array}{c}0,265 \\
(* *)\end{array}$ & $\begin{array}{c}0,334 \\
(* *)\end{array}$ & $\begin{array}{c}0,255 \\
(* *)\end{array}$ & $\begin{array}{c}0,263 \\
(* *)\end{array}$ & $\begin{array}{c}0,273 \\
(* *)\end{array}$ & $\begin{array}{c}0,312 \\
(* *)\end{array}$ & $\begin{array}{c}0,247 \\
(* *)\end{array}$ & $\begin{array}{c}0,213 \\
(* *)\end{array}$ & $\begin{array}{c}0,299 \\
(* *)\end{array}$ & $\begin{array}{c}0,188 \\
(* *)\end{array}$ \\
\hline Justiça & & & & $\begin{array}{c}0,222 \\
(* *)\end{array}$ & $\begin{array}{c}0,210 \\
(* *)\end{array}$ & $\begin{array}{c}0,231 \\
(* *)\end{array}$ & $\begin{array}{c}0,231 \\
(* *)\end{array}$ & $\begin{array}{c}0,190 \\
(* *)\end{array}$ & $\begin{array}{c}0,248 \\
(* *)\end{array}$ & $\begin{array}{c}0,194 \\
(* *)\end{array}$ & $\begin{array}{c}0,188 \\
(* *)\end{array}$ & $\begin{array}{c}0,165 \\
(* *)\end{array}$ & $\begin{array}{c}0,120 \\
(* *)\end{array}$ \\
\hline Transporte & & & & & $\begin{array}{c}0,447 \\
(* *)\end{array}$ & $\begin{array}{c}0,333 \\
(* *)\end{array}$ & $\begin{array}{c}0,323 \\
(* *)\end{array}$ & $\begin{array}{c}0,328 \\
(* *)\end{array}$ & $\begin{array}{c}0,321 \\
(* *)\end{array}$ & $\begin{array}{c}0,331 \\
(* *)\end{array}$ & $\begin{array}{r}0,347 \\
(* *)\end{array}$ & $\begin{array}{c}0,345 \\
(* *)\end{array}$ & $\begin{array}{c}0,336 \\
(* *)\end{array}$ \\
\hline $\begin{array}{l}\text { Estradas e } \\
\text { rodovias }\end{array}$ & & & & & & $\begin{array}{c}0,418 \\
(* *)\end{array}$ & $\begin{array}{c}0,389 \\
(* *)\end{array}$ & $\begin{array}{c}0,408 \\
(* *)\end{array}$ & $\begin{array}{c}0,407 \\
(* *)\end{array}$ & $\begin{array}{c}0,323 \\
(* *)\end{array}$ & $\begin{array}{c}0,299 \\
(* *)\end{array}$ & $\begin{array}{c}0,329 \\
(* *)\end{array}$ & $\begin{array}{c}0,243 \\
(* *)\end{array}$ \\
\hline $\begin{array}{c}\text { Fornecimento } \\
\text { de água }\end{array}$ & & & & & & & $\begin{array}{c}0,767 \\
(* *)\end{array}$ & $\begin{array}{c}0,557 \\
(* *)\end{array}$ & $\begin{array}{c}0,575 \\
(* *)\end{array}$ & $\begin{array}{c}0,404 \\
(* *)\end{array}$ & $\begin{array}{c}0,298 \\
(* *)\end{array}$ & $\begin{array}{c}0,233 \\
(* *)\end{array}$ & $\begin{array}{c}0,212 \\
\left(*^{*}\right)\end{array}$ \\
\hline $\begin{array}{l}\text { Serviço de } \\
\text { esgoto }\end{array}$ & & & & & & & & $\begin{array}{c}0,640 \\
(* *)\end{array}$ & $\begin{array}{c}0,529 \\
(* *)\end{array}$ & $\begin{array}{c}0,378 \\
(* *)\end{array}$ & $\begin{array}{c}0,283 \\
(* *)\end{array}$ & $\begin{array}{c}0,222 \\
(* *)\end{array}$ & $\begin{array}{c}0,193 \\
(* *)\end{array}$ \\
\hline $\begin{array}{l}\text { Recolhimento } \\
\text { de lixo }\end{array}$ & & & & & & & & & $\begin{array}{c}0,492 \\
(* *)\end{array}$ & $\begin{array}{c}0,369 \\
(* *)\end{array}$ & $\begin{array}{c}0,325 \\
(* *)\end{array}$ & $\begin{array}{c}0,240 \\
(* *)\end{array}$ & $\begin{array}{c}0,243 \\
(* *)\end{array}$ \\
\hline Energia Elétrica & & & & & & & & & & $\begin{array}{c}0,527 \\
(* *)\end{array}$ & $\begin{array}{c}0,353 \\
(* *)\end{array}$ & $\begin{array}{c}0,317 \\
(* *)\end{array}$ & $\begin{array}{c}0,259 \\
(* *)\end{array}$ \\
\hline Telefone Fixo & & & & & & & & & & & $\begin{array}{c}0,614 \\
(* *)\end{array}$ & $\begin{array}{c}0,404 \\
(* *)\end{array}$ & $\begin{array}{c}0,401 \\
(* *)\end{array}$ \\
\hline $\begin{array}{l}\text { Telefone } \\
\text { Celular }\end{array}$ & & & & & & & & & & & & $\begin{array}{c}0,435 \\
(* *)\end{array}$ & $\begin{array}{c}0,497 \\
(* *)\end{array}$ \\
\hline Bancos & & & & & & & & & & & & & $\begin{array}{c}0,521 \\
(* *)\end{array}$ \\
\hline
\end{tabular}

(**) Correlação é significante no nível 0,01 (2-tailed). 
Após a avaliação do grau de correlação entre as variáveis buscou-se utilizar uma técnica que permitisse examinar se existiam dimensões subjacentes àquelas medidas que pudessem sintetizar as informações nelas contidas. Para isso, optouse pela análise fatorial ${ }^{9}$. O procedimento seguinte foi a análise da distribuição de freqüências das variáveis, avaliando sua normalidade.

Examinando os eigenvalues ${ }^{10}$ verificou-se que três fatores encontravam-se acima de 1 (critério de Kaiser). O primeiro fator corresponde a 39,8\%, o segundo a $11,7 \%$ e o terceiro a $10,9 \%$ do total dos eigenvalues do modelo, ou seja, explicam juntos $62,6 \%$ das variações das medidas originais. Dessa forma, avaliou-se satisfatório a representativa do real.

Em seguida analisou-se a matriz fatorial (Tabela 2) para identificar, pelos factor loadings ${ }^{11}$, quais as variáveis que melhor se correlacionam com cada fator. A estratégia de rotação para a matriz fatorial utilizada foi o método Varimax com a Normalização de Kaiser e o método de extração foi o de Análise do Componente Principal. Na matriz rodada, as distinções entre os factor loadings são maiores e a composição dos fatores é mais fortemente revelada. O fator 1 reúne as informações relativas as variáveis fornecimento de água, serviços de esgoto, recolhimento de lixo, energia elétrica. O fator 2 é composto das variáveis telefone fixo, telefone celular, bancos, fabricação de carros. E o fator 3 reúne as variáveis educação, saúde, aposentadoria e previdência e justiça.

\footnotetext{
9 É uma análise multivariada que se aplica à busca de identificação de fatores num conjunto de medidas realizadas. A identificação de novas dimensões na análise fatorial recorre à análise de componentes principais, que seria a identificação da função que melhor discrimina os objetos e, depois, deriva a função ortogonal. As medidas seriam os escores e sua unidade poderia ser a menor medida entre os pontos (PEREIRA, 2001).

10 O eigenvalue é a medida de quanto a variância total das medidas realizadas pode ser explicada pelo fator. O eigenvalue avalia a contribuição do fator ao modelo construído pela análise fatorial, sendo que um valor pequeno sugere pequena contribuição do fator na explicação das variações das variáveis originais (PEREIRA, 2001).

11 O factor loading é a medida de correlação entre a função derivada e as medidas originais (PEREIRA, 2001).
} 
Tabela 2

Matriz fatorial

\begin{tabular}{|l|c|c|c||c|c|c|}
\hline & \multicolumn{2}{|c||}{ Matriz de componentes } & \multicolumn{3}{c|}{$\begin{array}{c}\text { Matriz de componentes } \\
\text { rotacionada }\end{array}$} \\
\hline & 1 & 2 & 3 & 1 & 2 & 3 \\
\hline Educação & 0,549 & 0,608 & & & & 0,800 \\
\hline Saúde & 0,579 & 0,639 & & & & 0,831 \\
\hline Aposentadoria e previdência & 0,552 & & & & & 0,665 \\
\hline Justiça & & & & & & 0,575 \\
\hline Transporte & 0,604 & & & & & \\
\hline Estradas e rodovias & 0,647 & & & & & \\
\hline Fornecimento de água & 0,706 & & $-0,508$ & 0,852 & & \\
\hline Serviço de esgoto & 0,703 & & $-0,539$ & 0,870 & & \\
\hline Recolhimento de lixo & 0,674 & & & 0,754 & & \\
\hline Energia Elétrica & 0,708 & & & 0,671 & & \\
\hline Telefone Fixo & 0,666 & & & & 0,659 & \\
\hline Telefone Celular & 0,612 & & & & 0,768 & \\
\hline Bancos & 0,578 & & & & 0,728 & \\
\hline Fabricação de carros & 0,521 & & & & 0,792 & \\
\hline
\end{tabular}

Extraction Method: Principal Component Analysis.

a 3 components extracted.

Extraction Method: Principal Component Analysis. Rotation Method: Varimax with Kaiser Normalization.

a Rotation converged in 5 iterations.

Pode-se observar no quadro acima que a análise fatorial identificou três grandes dimensões que tendem a orientar a resposta dos entrevistados ${ }^{12}$ : a primeira dimensão diz respeito aos serviços ditos públicos. A segunda dimensão inclui serviços que foram privatizados recentemente. O processo de privatização teve bastante cobertura da mídia e gerou debates na imprensa escrita e televisiva. Finalmente, no outro extremo, tem-se um conjunto de serviços que são percebidos pela população como sendo o domínio por excelência da iniciativa privada: a produção de automóveis, os serviços bancários etc. Um outro dado relevante do

\footnotetext{
12 A análise fatorial considerando a amostra apenas de São Paulo (total de 714 entrevistados) mostrou um padrão semelhante, ou seja, também foram identificadas três dimensões de avaliação dos serviços públicos. Entretanto, no caso da amostra paulista os serviços de telefonia fixa tiveram a mesma avaliação que os serviços como o setor elétrico e saneamento básico, ficando na dimensão de serviços públicos tradicionais para os eleitores brasileiros. Já no caso da amostra nacional a telefonia fixa ficou agrupada entre os serviços considerados de maior peso do setor privado. Esse resultado sugere a hipótese de que a telefonia fixa teve percepções distintas no estado de São Paulo comparada ao restante do país.
} 
padrão de respostas observado para esse conjunto de questões aparece quando cruzamos dois a dois os itens tirados de cada uma dessas dimensões.

Uma análise detida desses cruzamentos mostra que o padrão das respostas dadas pelos entrevistados está longe de ser aleatório. De fato, na Tabela 3, abaixo, vê-se que enquanto que a imensa maioria tende a concordar que serviços como educação são de responsabilidade intrínseca do Estado, esse acordo é menos tranqüilo quando se trata de serviços privatizados, como a energia elétrica. Entretanto, todos os que consideram a energia elétrica como uma área que deveria ser restrita à ação do Estado tendem a responder o mesmo para a educação, enquanto que um número significativo de eleitores aceita que a educação é um dever do Estado, mas não estende essa conclusão para a energia. O mesmo comportamento também se observa com relação à fabricação de carros. Aqui aumenta a percepção de que essa atividade é uma atribuição do setor privado: $68,5 \%$ dos entrevistados atribuem ao setor privado a responsabilidade pela fabricação de automóveis, enquanto apenas 23,4\% dos entrevistados consideram que a educação é responsabilidade privada.

\section{Tabela 3}

Responsabilidade pela energia elétrica de acordo com a responsabilidade pela educação e fabricação de carros (\%)

\begin{tabular}{|c|c|c|c||c|c|c|}
\hline \multirow{2}{*}{ Energia Elétrica } & \multicolumn{2}{|c||}{ Educação } & \multirow{2}{*}{ Total } & \multicolumn{2}{c|}{ Fabricação de carros } & \multirow{2}{*}{ Total } \\
\cline { 2 - 3 } & Governo & Privado & & Governo & Privado & \\
\hline Governo & $80,3 \%$ & $55,3 \%$ & $74,5 \%$ & $90,8 \%$ & $66,4 \%$ & $53,3 \%$ \\
Res. ajustado & 11,9 & $-11,9$ & & 12,7 & $-12,7$ & \\
\hline Privado & $19,7 \%$ & $44,7 \%$ & $25,5 \%$ & $9,2 \%$ & $33,6 \%$ & $25,9 \%$ \\
Res. ajustado & $-11,9$ & 11,9 & & $-12,7$ & 12,7 & \\
\hline Total & 1855 & 562 & 2417 & 751 & 1635 & 2386 \\
\hline
\end{tabular}

\begin{tabular}{lccc} 
& Value & df & Asymp. Sig. (2-sided) \\
\hline Pearson Chi-Square - Energia Elétrica by Educação & 85,653 & 1 &, 000 \\
\hline Pearson Chi-Square - Energia Elétrica by Fabricação de Carros & 106,057 & 1 &, 000
\end{tabular}

a. Computed only for a $2 \times 2$ table

b. 0 cells $(, 0 \%)$ have expected count less than 5 . The minimum expected count is 104,79 .

A Tabela 4, abaixo, evidencia o mesmo padrão observado anteriormente: a maioria tende a concordar que serviços como educação são de responsabilidade do Estado, enquanto uma parcela menor considera o mesmo com relação à fabricação de carros. Mas entre aqueles que consideram a fabricação de carros como uma 
área que deveria ser restrita à ação do Estado, poucos dão uma resposta diferente para a educação. Da mesma maneira, quem considera a educação uma atividade privada, dá a mesma resposta para a fabricação de carros.

Tabela 4

Responsabilidade pela fabricação de carros de acordo com a responsabilidade pela educação (\%)

\begin{tabular}{|c|c|c|c|}
\hline \multirow{2}{*}{ Fabricação de carros } & \multicolumn{2}{|c|}{ Educação } & \multirow{2}{*}{ Total } \\
\cline { 2 - 3 } & Governo & Privado & \\
\hline Governo & $35,9 \%$ & $16,8 \%$ & $31,4 \%$ \\
Res. ajustado & 8,5 & $-8,5$ & \\
\hline Privado & $64,1 \%$ & $83,2 \%$ & $68,6 \%$ \\
Res. ajustado & $-8,5$ & 8,5 & 2370 \\
\hline Total & 1815 & 555 & Asymp. Sig. (2-sided) \\
\hline \multicolumn{7}{c}{ Value } & df &, 000 \\
\hline
\end{tabular}

O resultado desta análise mostra que há um padrão perfeitamente coerente nas respostas que os entrevistados deram quando sustentam ou não a responsabilidade do Estado para o provimento de cada um dos setores que foram apresentados à sua consideração. É, portanto, possível se produzir uma escala reunindo as respostas dadas pelos entrevistados em cada um dos itens que analisamos acima ${ }^{13}$. Os resultados desse exercício podem ser vistos no Tabela 5.

13 Observe-se que os itens escolhidos para compor essa escala foram escolhidos porque estão associados a cada uma das diferentes dimensões reveladas pela análise fatorial que analisamos acima. Em cada fator, escolhemos como representativa a variável que produzia maior polarização, o que permite criar uma escala com distribuição mais homogênea. Para as técnicas de produção da escala de Guttman, ver Buchanan (1974). 
Tabela 5

Escala de atitudes sobre a presença do Estado na economia

\begin{tabular}{|c|c|c|c|c|}
\hline \multirow{2}{*}{ Posição na escala } & \multicolumn{2}{|c|}{ Ação do Estado no provimento dos serviços/produtos } & \multirow{2}{*}{ Total } \\
\cline { 2 - 4 } & Educação & Energia elétrica & $\begin{array}{c}\text { Fabricação de } \\
\text { carros }\end{array}$ & \\
\hline Privatismo & $\mathrm{N}$ & $\mathrm{N}$ & $\mathrm{N}$ & $24,8 \%$ \\
\hline Estado mínimo & $\mathrm{S}$ & $\mathrm{N}$ & $\mathrm{N}$ & $14,3 \%$ \\
\hline Desenvolvimentista & $\mathrm{S}$ & $\mathrm{S}$ & $\mathrm{N}$ & $37,1 \%$ \\
\hline Estatista & $\mathrm{S}$ & $\mathrm{S}$ & $\mathrm{S}$ & $23,8 \%$ \\
\hline Total (100\%) & & & & $(2357)$ \\
\hline
\end{tabular}

O índice de reprodutibilidade dessa escala é bastante alto, 96\%, o que está bem acima do mínimo usualmente aceito para escalas desse tipo, que é de $90 \%$. Essa escala indica que $25 \%$ da população brasileira apresentou um padrão de respostas bastante próximo daquele que poderia se descrito como privatista. Para esses eleitores, o Estado não deveria ter nenhuma participação nas atividades econômicas, inclusive quando consideram o provimento de serviços básicos, como saúde e educação. Outros $14 \%$ dos entrevistados apresentaram um padrão de respostas que permitiria classificá-los como favoráveis àquilo que a literatura chama de Estado mínimo: a presença do Estado só é aceitável para o provimento de serviços básicos. Todos os outros setores da economia deveriam ficar nas mãos da iniciativa privada. A maior parte dos entrevistados defende uma posição mais próxima daquela que a literatura chama de desenvolvimentismo: a presença do Estado na economia é bem-vinda, não apenas no provimento de serviços essenciais, mas também em setores chamados estratégicos para o desenvolvimento: o fornecimento de energia elétrica, telefonia etc. Finalmente, para $24 \%$ dos eleitores, o Estado é sempre um ator preferencial na economia: sua intervenção é bem-vinda em todos os setores; posição que foi classificada como sendo "estatista".

Tendo-se obtido a escala, uma questão importante que se coloca é estabelecer quais variáveis estão correlacionadas com cada uma das posições descritas acima. Para responder a essa questão, fizemos análises de regressão tomando como variável dependente cada uma das posições produzidas pela escala, isoladamente $^{14}$. Cada uma das análises de regressão levou em consideração um

\footnotetext{
14 Para tanto dicotomizamos a escala de 4 maneiras diferentes, cada uma delas isolando um padrão de resposta. Em seguida fizemos as regressões com a variável dicotomizada.
} 
conjunto fixo de variáveis: a avaliação que o entrevistado fazia do governo federal (na época, o governo FHC); a decisão de voto do eleitor no primeiro e no segundo turno; auto-posicionamento na escala de ideologia; sexo; idade; escolaridade; avaliação do serviço público; nível de satisfação com o serviço público brasileiro; interesse por política; e nível de satisfação do eleitor com a democracia no Brasil.

Um resumo dos resultados dessa análise podem ser vistos no Quadro 2, abaixo.

\section{Quadro 2}

Variáveis que se revelaram preditoras de cada posição na escala de atitudes sobre a presença do estado na economia

\begin{tabular}{|c|c|}
\hline Posição na escala & Variáveis preditoras \\
\hline Privatismo & $\begin{array}{l}\text { Escolaridade } \\
\text { Voto para presidente no primeiro turno } \\
\text { Idade } \\
\text { Avaliação dos serviços públicos }\end{array}$ \\
\hline Estado mínimo & $\begin{array}{c}\text { Escolaridade } \\
\text { Avaliação do governo FHC }\end{array}$ \\
\hline Desenvolvimentista & $\begin{array}{l}\text { Avaliação geral do governo FHC } \\
\text { Idade } \\
\text { Avaliação da Democracia }\end{array}$ \\
\hline Estatista & $\begin{array}{l}\text { Escolaridade } \\
\text { Voto para presidente no segundo turno } \\
\text { Avaliação dos serviços públicos }\end{array}$ \\
\hline
\end{tabular}

Na Tabela 6, analisamos com maior atenção o comportamento das variáveis sócio-demográficas com relação a essa escala. Essa tabela nos indica que a posição do eleitor na escala acima pode ser explicada, em parte, em função de variáveis sócio-demográficas, às quais, em conjunto, também expressam a maior ou menor vulnerabilidade do entrevistado às pressões do mercado de trabalho. De fato, quando se observa a correlação entre as posições na escala e as variáveis escolaridade e idade, têm-se um padrão cruzado. Os mais escolarizados e mais jovens tendem a assumir a posição de Estado mínimo, e valorizam a ação da iniciativa privada no fornecimento em grande parte dos serviços. Já os entrevistados mais velhos e menos escolarizados tendem a assumir o extremo oposto da escala, e valorizam a ação estatal em todas as áreas e serviços, inclusive na produção de bens de consumo, como é o caso da fabricação de carros. 
Dois fatores podem concorrer para esse padrão de associação. Em primeiro lugar há que se considerar o fator da experiência social comum vivida por cada coorte de eleitores. Os eleitores mais velhos viveram boa parte da sua vida sob a égide incontestável da ideologia do estado desenvolvimentista. Para esse grupo é quase inimaginável um serviço não estatal: o estado sempre foi (e, portanto, deve continuar sendo) o grande elemento dinamizador e orientador da atividade social e econômica do país. Por outro lado, a vulnerabilidade específica vivida pelo eleitor mais velho e menos escolarizado no mercado de trabalho, faz com que esse seja particularmente atraído pelo modelo autárquico e não competitivo que costuma vir associado ao estatismo.

\section{Tabela 6}

Matriz de Correlação de Pearson: varáveis sócio-demográficas e a escala de atitudes acerca da presença do Estado na economia

\begin{tabular}{|c|c|c|}
\hline & Escolaridade & Idade \\
\hline Privatismo & 0,020 & $0,087(* *)$ \\
& 0,327 & 0,000 \\
\hline Estado Mínimo & $0,110(* *)$ & $-0,101(* *)$ \\
& 0,000 & 0,000 \\
\hline Desenvolvimentismo & $0,081(* *)$ & $-0,071(* *)$ \\
& 0,000 & 0,000 \\
\hline Estatismo & $0,202(* *)$ & $0,075(* *)$ \\
& 0,000 & 0,000 \\
\hline
\end{tabular}

** Correlation is significant at the 0.01 level (2-tailed).

* Correlation is significant at the 0.05 level (2-tailed).

Por outro lado, consideremos agora as duas posições que denominamos privatismo e Estado desenvolvimentista. Aqui, os entrevistados tendem a concordar com um espaço mínimo de atuação do Estado, associado aos direitos essenciais da saúde e educação, mas discordam quanto à extensão da atuação do Estado para outros serviços - água, luz, telefonia etc. Para aqueles que chamamos de desenvolvimentistas, esses serviços precisam permanecer sob a tutela do governo e serem ofertados à partir da ação do Estado. Para aqueles que se encaixam no que chamamos de "privatismo", esses serviços devem ser ofertados a partir de uma lógica de mercado e com a participação direta da iniciativa privada. Esses serviços foram objeto de um forte processo de privatização durante os anos $\mathrm{FHC}$ e polêmica de sua estatização permanece em aberto ainda durante o governo Lula. Não surpreendentemente, as variáveis de cunho político apresentam-se como 
importantes preditoras do comportamento dos entrevistados: a avaliação que o eleitor faz do governo FHC e a orientação de seu voto no primeiro turno. De fato, como vemos no quadro abaixo (Tabela 7), há uma associação negativa e significativa entre a posição favorável ao maior intervencionismo estatal (estado desenvolvimentista) e a avaliação do governo FHC. Isto é quanto mais positiva é essa avaliação, menor é a probabilidade de que o entrevistado concorde com um Estado atuando no fornecimento de todos os serviços.

Ademais, os estatistas diferem dos demais quanto à avaliação dos serviços públicos no Brasil. Esses eleitores tendem a avaliar mais positivamente os serviços públicos no Brasil do que os demais grupos. Já os privatistas colocam-se na posição oposta: estes eleitores tendem a apresentar uma visão mais negativa dos serviços públicos, quando comparados aos desenvolvimentistas e aos favoráveis ao Estado mínimo.

\section{Tabela 7}

Matriz de Correlação de Pearson: atitudes políticas e a escala de atitudes acerca da presença do Estado na economia

\begin{tabular}{|c|c|c|c|c|}
\hline & $\begin{array}{c}\text { Avaliação } \\
\text { governo FHC }\end{array}$ & $\begin{array}{c}\text { Intenção de } \\
\text { voto } 2^{\circ} \text { turno }\end{array}$ & $\begin{array}{c}\text { Avaliação do } \\
\text { serviço público }\end{array}$ & $\begin{array}{c}\text { Avaliação da } \\
\text { democracia }\end{array}$ \\
\hline Privatismo & 0,030 & $0,100(* *)$ & $-0,073(* *)$ & $-0,010$ \\
& 0,140 & 0,000 & 0,000 & 0,624 \\
& 2373 & 1996 & 2395 & 2258 \\
\hline Estado mínimo & $0,056(* *)$ & $-0,001$ & $-0,002$ & $-0,055(* *)$ \\
& 0,006 & 0,966 & 0,935 & 0,009 \\
& 2373 & 1996 & 2395 & 2258 \\
\hline Desenvolvimentismo & $-0,071(* *)$ & $-0,042$ & $-0,023$ & $0,045\left(^{*}\right)$ \\
& 0,001 & 0,058 & 0,268 & 0,033 \\
& 2373 & 1996 & 2395 & 2258 \\
\hline Estatismo & 0,003 & $-0,051(*)$ & $0,101(* *)$ & 0,006 \\
& 0,892 & 0,022 & 0,000 & 0,778 \\
& 2373 & 1996 & 2395 & 2258 \\
\hline
\end{tabular}

** Correlation is significant at the 0.01 level (2-tailed).

* Correlation is significant at the 0.05 level (2-tailed). 


\section{Conclusões preliminares}

O trabalho apresentado constitui uma contribuição para o debate acerca das atitudes e valores da sociedade que foram mobilizados pelo processo de privatização das empresas estatais durante o governo FHC.

A literatura sobre essa questão mostra quão essas questões estão arraigadas no imaginário social brasileiro e como, ao longo dos anos 1980, parcelas significativas da elite brasileira mudaram sua percepção acerca do papel do Estado no desenvolvimento econômico. Apesar disso, estudos sobre as atitudes da população com relação a essa temática são praticamente inexistentes. Baker (2002) sugere que essa lacuna tem um viés teórico: a literatura brasileira sobre comportamento político tende a reforçar a percepção de que a baixa escolaridade do eleitorado brasileiro e a forte presença do clientelismo reforçam os componentes irracionais do comportamento desses eleitores. Assim, seria um exercício fútil buscar avaliar as posições desse eleitorado sobre questões mais complexas que polarizam o debate entre a elite. O eleitorado brasileiro seria incapaz de avaliar essas questões e tomar posições coerentes nesse debate.

Os resultados desse trabalho lançam dúvidas sobre esse diagnóstico sombrio. Os dados apresentados permitiram a identificação de padrões diferenciados (mas coerentes) de atitudes do eleitorado sobre o tema da privatização. Ademais foi possível estabelecer correlações significativas entre essas atitudes e outras questões que marcaram a agenda da campanha eleitoral de 2002. Esses resultados mostram que a análise das atitudes do eleitorado acerca de temas que marcam o debate nacional não é um exercício fútil. É necessário aprofundar esses estudos para averiguar o quanto questões dessa natureza estão consolidadas no comportamento do eleitorado. 


\section{Referências Bibliográficas}

ALMEIDA, M. H. T. Negociando a reforma: a privatização de empresas públicas no Brasil. Dados - Revista de Ciências Sociais, v. 42, n. 3, p. 421-452, 1999.

ARRETCHE, M. Federalismo e relações inter-governamentais no Brasil: a reforma de programas sociais. Dados - Revista de Ciências Sociais, v. 45, n. 3, p. 431-458, 2002.

BAKER, A. Reformas liberalizantes e aprovação presidencial: a politização dos debates da política econômica no Brasil. Dados - Revista de Ciências Sociais, v. 45, n. 1, p. 77-98, 2002.

BUCHANAN, W. Undestanding political variables. New York: Charles Scribner's Sons, 1974.

DINIZ, E. Empresariado e projeto neoliberal na América Latina: uma avaliação dos anos 80. Dados - Revista de Ciências Sociais, v. 34, n. 3, p. 349-378, 1991.

Empresariado, Estado e desenvolvimento: novas tendências no limiar do novo milênio. Texto apresentado no $3 .^{\circ}$ Encontro da Associação Brasileira de Ciência Política, Niterói: Associação Brasileira de Ciência Política, 2002.

FIORINA, M. Retrospective voting in American national elections. New Haven: Yale University Press, 1981.

GLYNN, C.; HERBST, S.; O'KEEFE, G. J.; SHAPIRO, R. Y. Public opinion. Boulder, CO: Westview Press, 1999.

GRAHAM, C.; SUKHTANKAR, S. Does economic crisis reduce support for markets and democracy in Latin America? Some evidence from survey of public opinion and well being. Journal of Latin America Studies, v. 36, n. 2, p. 349-377, 2004.

HARROP, M.; MILLER, W. L. Elections and Voters: a comparative introduction. New York: New Amsterdam Books, 1987.

KUCZYNSKY, P.P. Reformando o Estado. In: KUCZYNSKY, P.-P.; WILLIAMSON, J. (eds.). Depois do Consenso de Washington: retomando o crescimento e a reforma na América Latina. São Paulo: Ed. Saraiva, 2004, p. 28-41. 
LIMA, M. R. S.; BOSCHI, R. R. Democracia e reforma econômica: a visão das elites brasileiras. Dados - Revista de Ciências Sociais, v. 38, n. 1, p. 7-30, 1995.

LOURENÇO NETO, S. Privatizações e suas conseqüências políticas e econômicas, um estudo preliminar. 2002. Apresentado no 3. Encontro da Associação Brasileira de Ciência Política, Niterói, Associação Brasileira de Ciência Política, 2002. Disponível em:

<http://www.cienciapolitica.org.br/encontro/poleco.htm>. Acesso em: 30 de Novembro de 2004.

MILLER, W.; SHANKS, M. J. The new American voter. Cambridge: Cambridge University Press, 1996.

NASCIMENTO, R. A mudança de papel do Estado brasileiro: uma análise dos anos 50 aos anos 90. In: BENECKE, D. W.; NASCIMENTO, R. (ed.). Opções de política econômica para o Brasil. Rio de Janeiro: Fundação Konrad Adenauer, 2003, p. 187-206.

PEREIRA, J. C. R. Análise de dados qualitativos: estratégias metodológicas para as ciências da saúde, humanas e sociais. São Paulo: Edusp, 2001.

RATTS $\varnothing$, J.; SØRENSEN, R. J. Explaining public sector reform: electoral interests or political structure? Presentation at the NOPSA-workshop "Kommunerne som politologisk laboratorium", Aalborg, Denmark, August 15-17 2002.

SINGER, A. Esquerda e direita no eleitorado brasileiro. São Paulo: Edusp, 2000.

WILLIAMSON, J. Nossa agenda e o Consenso de Washington. In: KUCZYNSKY, P.-P.; WILLIAMSON, J. (org.). Depois do Consenso de Washington: retomando o crescimento e a reforma na América Latina. São Paulo: Ed. Saraiva, 2004, p. 283-291. 